\title{
ARTIGOS
}

Submetido 14.01.2014. Aprovado 02.09.2014

Avaliado pelo processo de double blind review. Editor Científico: João Porto de Albuquerque

DOI: http://dx.doi.org/10.1590/So034-759020150505

\section{REMONTANDO A REDE DE ATORES NA IMPLANTAÇÃO DE UM SISTEMA DE INFORMAÇÃO EM SAÚDE}

\author{
Reassembling the actor-network in the deployment of a health information system \\ Remontando la red de actores en la implantación de un sistema de \\ información en salud
}

\section{MARCELO FORNAZIN \\ fornazin@gmail.com \\ Professor da Universidade do \\ Estado do Rio de Janeiro, Instituto \\ de Matemática e Estatística - Rio de \\ Janeiro - RJ, Brasil}

\section{LUIZ ANTONIO JOIA}

luiz.joia@fgv.br

Professor da Fundação Getulio

Vargas, Escola Brasileira de

Administração Pública e de

Empresas - Rio de Janeiro - RJ, Brasil

\section{RESUMO}

Este trabalho, baseando-se na Teoria Ator-Rede, visa analisar a implantação de um sistema de informação em saúde (SIS) em um hospital público brasileiro, seguindo os atores envolvidos nas controvérsias ocorridas durante a trajetória do projeto. As mudanças observadas durante a implantação do sistema revelam que a noção de sucesso foi construída coletivamente, por meio da negociação de dispositivos de "interessamento" introduzidos durante o projeto.

PALAVRAS-CHAVE | Sistemas de informação em saúde, Teoria Ator-Rede, administração pública, governo eletrônico, tecnologia da informação.

\section{ABSTRACT}

This paper, based on the Actor-Network Theory, intends to analyze the dynamics of implementation of a Health Information System (HIS) in a Brazilian public hospital by following the actors involved in controversies occurred throughout the project trajectory. The changes observed over the course of the system implementation reveal that the concept of success was jointly developed via negotiation of devices of interessement introduced during the project.

KEYWORDS I Health information systems, actor-network theory, public administration, electronic government, information technology.

\section{RESUMEN}

Este trabajo, se basa en la Teoría Actor-Red, busca analizar la implantación de un sistema de información en salud (SIS) en un hospital público brasileño, siguiendo a los actores envueltos en las controversias ocurridas durante la trayectoria del proyecto. Los cambios observados durante la implantación del sistema revelan que la noción de éxito fue construida colectivamente, por medio de la negociación de 'dispositivos de interés' introducidos durante el proyecto.

PALABRAS-CLAVE I Sistemas de información en salud, Teoría Actor-Red, administración pública, gobierno electrónico, tecnología de la información. 


\section{INTRODUÇÃO}

Os estudos sobre implantação de sistemas de informação em saúde (SIS) em países em desenvolvimento têm evidenciado o caráter político e heterogêneo de tais empreitadas. Ou seja, para que os SIS sejam desenvolvidos e implantados com sucesso, faz-se necessário construir e mobilizar redes de atores que os suportem ao longo do tempo (Braa, Monteiro, \& Sahay, 2004; Kimaro \& Nham possa, 2005; Sahay, Sæbø, \& Braa, 2013; Sheikh \& Braa, 2011).

No Brasil, os desafios inerentes à implantação de SIS levam ao questionamento sobre como esses sistemas podem ser desenvolvidos e implantados com sucesso no País. Um exemplo disso é o sistema E-Hosp, cuja implantação em um hospital público foi considerada ambiciosa, mas que, ao final, ficou aquém dos objetivos inicialmente planejados. Ainda assim, os atores envolvidos nesse projeto consideraram a implantação do E-Hosp exitosa, diante dos problemas encontrados durante o processo.

Dessa forma, este trabalho visa analisar o caso do E-Hosp, objetivando: a) problematizar a noção de sucesso associada à implantação desse SIS, a qual decorre do atingimento de objetivos previamente estabelecidos; e b) descrever como a implantação de um SIS ocorre por meio de negociações envolvendo diversos atores heterogêneos, evidenciando, assim, a complexidade sociotécnica de tal empreendimento.

O caso em questão foi analisado de maneira longitudinal, tendo por base a Teoria Ator-Rede (Callon, 1986; Latour, 1997, 2010). Desse modo, o trabalho visa contribuir para a literatura sobre SIS nos países em desenvolvimento, ao trazer uma explicação baseada na “ciência em ação" (Latour, 1997), nas atividades ocorridas ao longo da implantação do SIS, onde o sucesso, em vez de resultar de uma atividade tecnicamente planejada, foi continuamente negociado e estabilizado em uma rede heterogênea, a qual se formou durante as controvérsias surgidas ao longo dessa implantação.

Este trabalho está organizado da seguinte maneira. Após esta introdução, apresenta-se o referencial teórico adotado, relacionando as pesquisas sobre SIS em países em desenvolvimento e a Teoria Ator-Rede. A seção seguinte clarifica os procedimentos metodológicos observados nesta pesquisa. Em seguida, apresen ta-se a trajetória de implantação do E-Hosp. Por fim, são expostas a discussão e as conclusões do artigo, suas limitações e uma agenda de pesquisa futura.

\section{REFERENCIAL TEÓRICO}

Este trabalho baseia-se em um referencial articulado em duas partes. A primeira aborda os estudos sobre SIS em países em desenvolvimento, os quais buscam compreender como a implantação de SIS pode sem bem-sucedida. A segunda parte apresenta a Teoria Ator-Rede e estudos em sistemas dinformação (SI) nela inspirados, de modo a compor um adequado referencial para compreender o processo de negociação que define o sucesso da implantação de um SIS.

\section{Sucesso e fracasso na implantação de sistemas de informação em países em desenvolvimento}

As pesquisas sobre SI em países em desenvolvimento têm discutido como os SI podem promover desenvolvimento econômico e social, bem como elencado os fatores associados ao sucesso ou fracasso na implantação de SI nos países do Sul Global.

Heeks, Mundy, e Salazar (1999) observaram que a implantação de SIS em países em desenvolvimento, na maioria das vezes, incorre em fracasso. Os resultados frustrantes de um projeto de SIS podem ser atribuídos a lacunas entre o cenário projetado durante a concepção do SIS e a realidade em que ele é implantado, como lacunas de infraestrutura, capacitação técnica e diferentes contextos institucionais. Mais recentemente, pesquisas têm afirmado que o desenvolvimento e a implantação de SI nesses países dependem da inserção das tecnologias da informação e comunicação (TIC) no contexto social de vários cenários organizacionais (Avgerou, 2010). Consequentemente, não existe uma fórmula única para desenvolver e implantar SI em países em desenvolvimento.

Adicionalmente, Braa et al. (2004) sustentam que o desenvolvimento e implantação de SIS é uma atividade intrinsecamente política. Dessa forma, a mobilização de uma rede de atores é fundamental para a sustentação e expansão dos SIS. Tais atores compreendem políticos, burocratas, representantes de organismos internacionais, pesquisadores, bem como artefatos técnicos, ou seja, infraestruturas e outros recursos tecnológicos. Com vistas à mobilização para suporte aos SIS, são, portanto, necessárias estratégias de projeto flexíveis e ações participativas (Braa et al., 2004). Pesquisas também identificaram que a mobilização ocorre em conjunto com a aprendizagem organizacional (Kimaro \& Nhampossa, 2005), bem como com o desenvolvimento de capacidades para uso dos SIS (Sheikh \& Braa, 2011). Desse modo, os estudos citados revelam que a implantação de SIS não deve se limitar ao enfoque tecnológico, mas também levar em consideração o ambiente local.

Por outro lado, pode-se notar que os estudos sobre SIS nos países em desenvolvimento, ao abordarem questões de sustentação e expansão dos SI, têm se concentrado, sobretudo, em análises em nível nacional. Assim, levam em conta, como atores, as organi- 
zações governamentais, internacionais, órgãos de fomento, entre outros (Braa et al., 2004; Kimaro \& Nhampossa, 2005; Sheikh \& Braa, 2011), ou seja, os trabalhos não abarcam os detalhes do dia a dia da implantação em um SIS. Este trabalho, portanto, visa contribuir com a literatura sobre SIS nos países em desenvolvimento ao se debruçar sobre o cotidiano da implantação de um SIS, evidenciando, assim, a sua complexidade sociotécnica.

No Brasil, embora estudos tenham evidenciado os aspectos sociais e políticos associados à implantação de SIS (Albuquerque, Prado, \& Machado, 2011; Joia \& Magalhães, 2009; Sun, 2010), as práticas no País têm sido desconsideradas, assim como a realidade heterogênea na qual esses empreendimentos se inserem. As implantações de SIS são tratadas como projetos técnicos, conduzidos de modo linear e seguindo metodologia preestabelecida, visando o atingimento de objetivos predefinidos. Este trabalho, portanto, problematiza a noção preestabelecida de sucesso, apresentando explicações baseadas em controvérsias e negociações que viabilizaram a implantação do sistema E-Hosp no hospital em análise. Para tal, o trabalho se inspira na Teoria Ator-Rede, a qual será apresentada na próxima seção.

\section{Teoria Ator-Rede e sistemas de informação}

A Teoria Ator-Rede, também referida pelo acrônimo ANT (Actor-Network Theory), tem embasado pesquisas em SI desde a década de 1990 (Ciborra \& Hanseth, 1998; Walsham, 1997) e, com maior intensidade, a partir do ano 2000. Essas pesquisas têm abrangido diversos contextos, tais como governo eletrônico (Heeks \& Stanforth, 2007), saúde (Braa et al., 2004; Sheikh \& Braa, 2011) e gestão baseada em processos (Albuquerque, 2012; Sarker, Sarker, \& Sidorova, 2006). Na América Latina, e especialmente no Brasil, pesquisas têm se baseado na ANT para estudo da inclusão digital (Andrade \& Urquhart, 2010; Teles \& Joia, 2011), geoprocessamento (Rajão \& Vurdubakis, 2013; Silva, 2007), política industrial de informática e inovação (Marques, 2004; Ramos, 2009) e governo eletrônico (Barbosa, 2008; Cavalheiro \& Joia, 2014).

Inicialmente, para a ANT, o que se tem porverdade não é algo exterior para ser descoberto, mas uma construção coletiva. Segundo Latour (1997, p. 72): “um fato é algo que é retirado do centro de controvérsias e coletivamente estabilizado”. Nesta pesquisa, apresenta-se como a implantação bem sucedida do SIS foi coletivamente estabilizado em uma rede sociotécnica a partir de diversas controvérsias que surgiram durante a implantação do sistema.

$\mathrm{Na}$ abordagem ANT, a construção coletiva do fato pode ser entendida por meio de um processo denominado tradução, em que "traduzir é deslocar [...] traduzir é também expressar na linguagem de alguém o que outros dizem e querem, por que eles atuam da maneira que o fazem e como eles se associam com os outros: é estabelecer alguém como porta-voz" (Callon, 1986, pp. 213-214). Ou seja, o sucesso na implantação do SIS é alcançado pela tradução dos diversos atores envolvidos no projeto para um objetivo comum, denominado Ponto de Passagem Obrigatória (PPO). Ademais, segundo Callon (1986), o processo de tradução compreende quatro momentos - problematização, “interessamento", engajamento e mobilização - conforme apresentado no Quadro 1.

\section{Quadro 1. Momentos do processo de tradução}

\begin{tabular}{|c|c|}
\hline Conceito & Definição \\
\hline Problematização & $\begin{array}{l}\text { Eles [os pesquisadores] determinaram um } \\
\text { conjunto de atores e definiram suas identidades, } \\
\text { de forma a se estabelecerem como um PPO } \\
\text { na rede de relacionamentos que estavam } \\
\text { construindo. Esse movimento duplo, que os } \\
\text { torna indispensáveis na rede, é o que chamamos } \\
\text { de problematização (Callon, 1986, p. 204). }\end{array}$ \\
\hline “interessamento" & $\begin{array}{l}\text { Interessar outros atores é criar dispositivos } \\
\text { que podem ser colocados entre eles e outras } \\
\text { entidades que queiram definir suas identidades } \\
\text { de outra maneira (Callon, 1986, p. 208) }\end{array}$ \\
\hline Engajamento & $\begin{array}{l}\text { Grupo de negociações multilaterais, } \\
\text { confrontações e truques que acompanham o } \\
\text { “interessamento”, habilitando o atores a terem } \\
\text { sucesso (Callon, 1986, p. 211) }\end{array}$ \\
\hline Mobilização & $\begin{array}{l}\text { Um conjunto de métodos usados pelos } \\
\text { pesquisadores para assegurar que os supostos } \\
\text { representantes das várias coletividades } \\
\text { relevantes estavam propriamente habilitados a } \\
\text { representar essas coletividades, de forma a não } \\
\text { serem por elas traídos (Callon, 1986, p. 196) }\end{array}$ \\
\hline
\end{tabular}

Fonte: Callon (1986)

Um fato, portanto, não é considerado verdade por suas características imanentes, mas pela associação de elementos heterogêneos que o estabilizaram (Callon, 1986; Latour, 1997). Isto é, o sucesso do SIS resulta dos diversos testes de força a que foi submetido, sendo sustentado pela rede de atores mobilizada em seu entorno.

Além disso, na ANT, o princípio da simetria generalizada sustenta que "não devemos alterar os registros quando nos movemos de aspectos técnicos para sociais do problema estudado" (Callon, 1986, p. 199). Ou seja, o sucesso do SIS não deve ser atribuído arbitrariamente a categorias - tais como, por exemplo, fatores técnicos, sociais ou econômicos -, mas relacionado às categorias que emergiram do próprio campo. Assim, a pesquisa baseou-se em um vocabulário mínimo da abordagem ANT 
e buscou ater-se às próprias categorias que emergiram durante a análise dos dados.

Fundamentando-se no paradigma crítico interpretativo dos estudos em SI (Mitev, 2006; Pozzebon, 2004; Walsham, 1995), alguns elementos comuns aos trabalhos inspirados na ANT podem ser, a seguir, destacados. Primeiramente, ao analisar as controvérsias ocorridas durante a construção de artefatos técnicos (Latour, 1997), a maioria dos trabalhos refere-se a ambientes complexos com múltiplos atores, cujas preferências muitas vezes divergem. Assim, tais estudos mostram a dimensão política da implantação de um SIS, ressaltando que o consenso não é algo dado ou simples de se obter, sendo necessárias diversas traduções (Callon, 1986; Latour, 1997) para alcançar sucesso na implantação de um SIS, algo que nem sempre acontece.

Pode-se também notar que, em tais trabalhos, a interação com o campo de pesquisa ocorre de maneira flexível, ou seja, pesquisas baseadas na abordagem ANT buscam identificar as associações entre atores heterogêneos, independentemente do nível de análise e do contexto (Callon, 1986; Latour, 1997). Desse modo, evita-se impingir uma teoria prévia sobre os dados, permitindo-se representar o caso de diferentes maneiras (Law, 1999). Assim, a ANT não diferencia, a priori, contextos simples ou complexos, bem como evita definir previamente atores micro ou macro, com essas categorias emergindo durante a análise empírica da pesquisa (Latour, 1997).

Ademais, os estudos baseados na ANT seguem uma perspectiva longitudinal. De acordo com Latour (1997), a abordagem ANT propõe seguir os atores ao longo da construção de artefatos técnicos e suas controvérsias, em vez de analisá-los após estarem estabilizados. Portanto, em vez de se coletarem informações em um momento específico, analisam-se o movimento e a formação de grupos ou redes (Latour, 1997), bem como as traduções ocorridas (Callon, 1986).

Desse modo, este trabalho inspira-se nos conceitos da Teoria Ator-Rede para descrever a implantação de um SIS em um hospital público brasileiro por meio de negociações que resultaram na sua estabilização no hospital em questão e em seu proclamado sucesso.

\section{PROCEDIMENTOS METODOLÓGICOS}

Este trabalho adotou o método de estudo de caso, em conjunto com a ANT, para analisar a implantação de um SIS em um hospital público brasileiro. Os estudos de caso vêm sendo utilizados como método de pesquisa em SI desde a década de 1980 (Benbasat, Goldstein, \& Mead, 1987), tendo-se tornado, nos últimos 30 anos, um importante método para pesquisas na área (Paré, 2004).
Os estudos de caso em SI, em sua maioria, adotam uma visão positivista (Paré, 2004). Este trabalho, porém, aproxima-se da perspectiva crítico-interpretativa (Mitev, 2006; Pozzebon, 2004; Walsham, 1995), a qual compreende os estudos baseados na ANT.

Os estudos de caso crítico-interpretativos, embora não compartilhem dos valores positivistas, também possuem critérios para assegurar sua qualidade. Pozzebon (2004) relaciona quatro critérios para avaliação da pesquisa interpretativa, considerando seus pressupostos ontológicos e epistemológicos, quais sejam: autenticidade, plausibilidade, crítica e reflexividade, conforme apresentado no Quadro 2 e descrito nos próximos parágrafos.

\section{Quadro 2. Critérios de qualidade na pesquisa crítico- interpretativa}

\begin{tabular}{l|l}
\hline Critério & Descrição \\
\hline Autenticidade & $\begin{array}{l}\text { O pesquisador esteve em contato com o campo, } \\
\text { ou seja, interagiu com participantes e acessou } \\
\text { documentos? }\end{array}$ \\
\hline Plausibilidade & $\begin{array}{l}\text { O trabalho faz sentido e traz contribuições para } \\
\text { os leitores? }\end{array}$ \\
\hline Crítica & $\begin{array}{l}\text { O texto motiva o leitor a repensar premissas a } \\
\text { respeito de seu trabalho? }\end{array}$ \\
\hline Reflexividade & $\begin{array}{l}\text { O pesquisador revela seu papel pessoal e seu } \\
\text { viés na pesquisa? }\end{array}$ \\
\hline
\end{tabular}

Fonte: Pozzebon (2004)

O trabalho buscou suportar sua autenticidade por meio da apresentação detalhada do caso, baseando-se no extenso material produzido durante a pesquisa, cuja etapa empírica desenvolveu-se ao longo de 2011 e 2012, durante a implantação do sistema E-Hosp. Conforme Latour (2010) recomenda, nos estudos da ciência em ação, deve-se reunir todo material ao alcance em um diário de bordo, a fim de se reconstruir a trajetória dos artefatos técnicos. Assim, um dos autores participou da equipe de implantação do projeto e, desse modo, reuniu múltiplas fontes de evidência por meio de: a) entrevistas; b) observações participante e não participante; e c) fontes documentais.

As entrevistas foram realizadas majoritariamente durante três etapas: i) levantamento dos sistemas legados do hospital; ii) levantamento da rotina de trabalho no hospital; e iii) preparação para simulação do sistema. Em cada etapa, foram realizadas entrevistas nos diversos setores do hospital, a saber: unidade de internação (médicos e enfermeiros), centro cirúrgico, ambulatório, farmácia, almoxarifado, financeiro e diretoria. Nas entrevistas, 
participaram o chefe do setor e um ou dois profissionais. As entrevistas duraram entre 30 minutos e uma hora cada, tendo sido tomadas notas sobre as práticas de trabalho dos profissionais, suas expectativas em relação ao sistema, bem como suas impressões sobre o seu funcionamento. Portanto, as citações neste trabalho não podem ser avaliadas ipsi literis, uma vez que são baseadas nas notas das entrevistas realizadas.

As observações foram realizadas de maneira participante e não participante durante as atividades coletivas da implantação do sistema, como reuniões de apresentação do projeto, reuniões para discussão de conceitos para parametrização do sistema, treinamentos e reuniões de preparação para utilização do sistema. Por fim, as fontes documentais basearam-se nos manuais de uso do sistema, atas de reuniões, $e$-mails, memorandos e outros meios de comunicação relacionados ao projeto.

As notas do material foram organizadas em ordem cronológica e por setor do hospital, a fim de permitir a reconstrução da cronologia dos eventos, bem como cruzar informações entre os setores. Em seguida, reconstruiu-se a trajetória do caso, a qual foi, por diversas vezes, discutida com outros profissionais que trabalharam no projeto, assim como com outros pesquisadores. Desse modo, como propõe Latour (2010), buscou-se fazer um diálogo entre a teoria e a prática, bem como estabelecer as ligações entre os diversos atores e, assim, garantir a plausibilidade do trabalho. Além disso, por se tratar de uma pesquisa crítico-interpretativa, este trabalho não buscou encontrar uma verdade objetiva e generalizável, mas, sim, entender como o sucesso na implantação do SIS resultou da negociação entre diversos atores e estabilização de uma rede heterogênea.

Este trabalho, ao apresentar controvérsias associadas à implantação do SIS, aproxima-se da perspectiva crítica. A abordagem ANT, embora não tenha um aspecto crítico explícito, ao reconstruir "a rede e as ações de seus constituintes, associado a uma recusa em fazer distinções apriorísticas ou em assumir algo como dado, habilita uma luz crítica para ser posta no que é assumido, o mundano e o status quo" (Doolin \& Lowe, 2002, p. 74). Essas controvérsias surgem a partir das diferenças entre as ações de políticos, analistas de sistemas e profissionais de saúde, assim como durante as negociações que ocorrem ao longo implantação do SIS. Desse modo, o trabalho buscou retratar uma realidade que pudesse levar os leitores à reflexão crítica.

Finalmente, os autores refletem sobre os resultados encontrados, apresentando seus pontos de vista a partir de seus respectivos posicionamentos na pesquisa. Conforme citado, um dos autores trabalhou ativamente na implantação do SIS em questão, obtendo acesso a documentos e reuniões, e interagindo com os profissionais de saúde. Esse autor fazia parte da equipe de trabalho do hospital, não tendo qualquer relação com a empresa que estava implantando o SIS. Coube ao outro autor, dado o seu não envolvimento direto com o projeto, a missão de tentar retirar qualquer viés porventura remanescente no trabalho. As reflexões consolidadas dos autores são expressas na seção conclusiva deste artigo.

\section{DESCRIÇÃO DO CASO}

Este estudo baseia-se na experiência de implantação do sistema de informação hospitalar E-Hosp no hospital HPT (os nomes originais foram trocados por questões de confidencialidade). Tal projeto teve início no ano de 2010 , tendo sido dado por concluído em dezembro de 2012. Assim, conforme apresentado na Figura 1, esta pesquisa concentra-se na implantação do sistema E-Hosp no hospital HPT ao longo do ano de 2011.

\section{Figura 1. Linha do tempo do projeto E-Hosp}

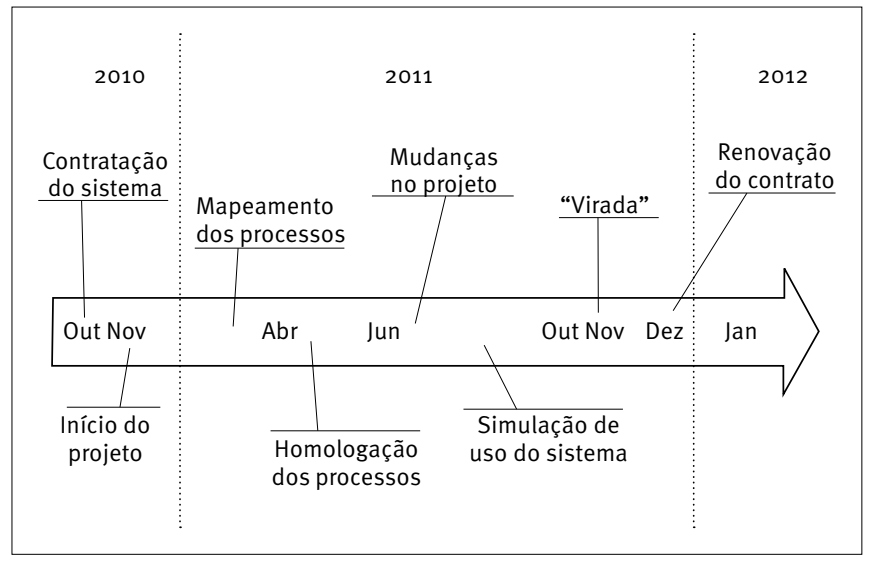

O HPT é vinculado ao governo brasileiro, sendo subordinado ao Ministério da Saúde (MS) e prestando serviços ao Sistema Único de Saúde (SUS), ou seja, é um hospital público e gratuito. Sob o ponto de vista assistencial, o HPT é um hospital geral, isto é, todos os dias internam-se pacientes, os quais passam por tratamentos clínicos e cirúrgicos. À época do projeto E-Hosp, a estrutura física do HPT compreendia 250 leitos, 15 salas de cirurgia e 60 consultórios. 0 parque de informática do hospital possuía cerca de 700 computadores, utilizados tanto na administração como nas atividades de saúde. A equipe de trabalho era composta por cerca de 1.800 servidores, compreendendo médicos, enfermeiros, outros profissionais de outras áreas da saúde e administradores.

A seguir, usando a abordagem ANT, é descrito o processo de implantação do E-Hosp no HPT de acordo com os quatro momentos de tradução apresentados no Quadro 1 (Callon, 1986), tal como realizado em vários estudos em SI (Albuquerque, 2012; Andrade \& Urquhart, 2010; Heeks \& Stanforth, 2007; Ramos, 2009; Teles \& Joia, 2011). 
Como é sabido, a saúde pública brasileira, embora fundamentada nos princípios de bem-estar social, encontra diversas dificuldades para efetivá-los. Desse modo, o MS, a fim de melhorar a gestão dos serviços de saúde e a capacidade de atendimento à população, lançou um projeto para estruturação de hospitais públicos, entre os quais estava incluído o HPT.

Segundo documentos do MS: “[...] o projeto de reestruturação tem por meta dotar os hospitais públicos de um alto padrão de atendimento, por meio de atividades voltadas à modernização dos processos de gestão". Para conduzir o projeto, o MS fez parceria com hospitais referência no atendimento hospitalar no Brasil, chamados aqui de HRefs, visando à transferência de tecnologia destes para os hospitais públicos.

Entre as atividades do projeto de reestruturação, estava, segundo documento oficial do MS: “[...] a modernização do parque computacional e dos sistemas informatizados do [HPT]". Isto é, o MS e os HRefs decidiram implantar um SI hospitalar para substituição do sistema legado, avaliado como incompleto para as necessidades do HPT. Assim, em outubro de 2010, após processo de seleção, uma empresa foi contratada para implantar o sistema E-Hosp no HPT. Conforme descrito no contrato e nas reuniões iniciais do projeto, cabia aos analistas de sistema da empresa contratada implantar o E-Hosp no hospital.

Para descrever o caso, o percurso dos analistas de sistema da empresa contratada incumbidos de implantar o E-Hosp no HPT foi seguido pelos pesquisadores, conforme pressupõe a abordagem ANT (Latour, 1997). O grupo de analistas era composto por um coordenador e cinco analistas e, uma vez que não foram observadas dissidências entre eles durante a implantação do sistema, optou-se por nomeá-los todos sob a rubrica "Analistas".

\section{Problematização}

Semelhantemente ao que é visto em Callon (1986), durante o momento de problematização, os Analistas, com base nas informações apresentadas no contrato e nas reuniões iniciais do projeto, formularam a hipótese de implantar o E-Hosp no HPT. 0 sucesso de tal implantação modernizaria a gestão do hospital. Além disso, a partir dos documentos analisados, pode-se notar que foram formuladas hipóteses a respeito das identidades e objetivos dos demais atores do projeto, os quais são resumidamente descritos a seguir.

O projeto de implantação do E-Hosp foi dotado de um "Comitê Executivo", definido em uma portaria administrativa do MS e composto por representantes do primeiro escalão do MS e dos HRefs. A esse comitê, cabiam as decisões estratégicas do projeto, como a definição dos objetivos, a avaliação dos resultados e as decisões referentes a questões orçamentárias. Os Analistas esperavam que o Comitê Executivo apoiasse tanto a implantação do E-Hosp como propostas de mudança no HPT.

O sistema E-Hosp foi definido pelos Analistas, a partir das orientações do projeto de reestruturação, como a ferramenta que levaria o HPT para um novo patamar de gestão. 0 sistema E-Hosp funcionaria em arquitetura web, sendo desenvolvido em uma plataforma tecnológica atualizada em relação ao sistema legado. Os Analistas também apresentaram um diagrama com os módulos do E-Hosp, conforme ilustrado na Figura 2. Tal diagrama evidenciava como o E-Hosp estaria presente nos diversos setores do HPT. Ademais, de acordo com o contrato, a implantação do E-Hosp abarcava, fundamentalmente, suas funcionalidades padrão, sem desenvolvimento de personalizações.

\section{Figura 2. Módulos do E-Hosp}

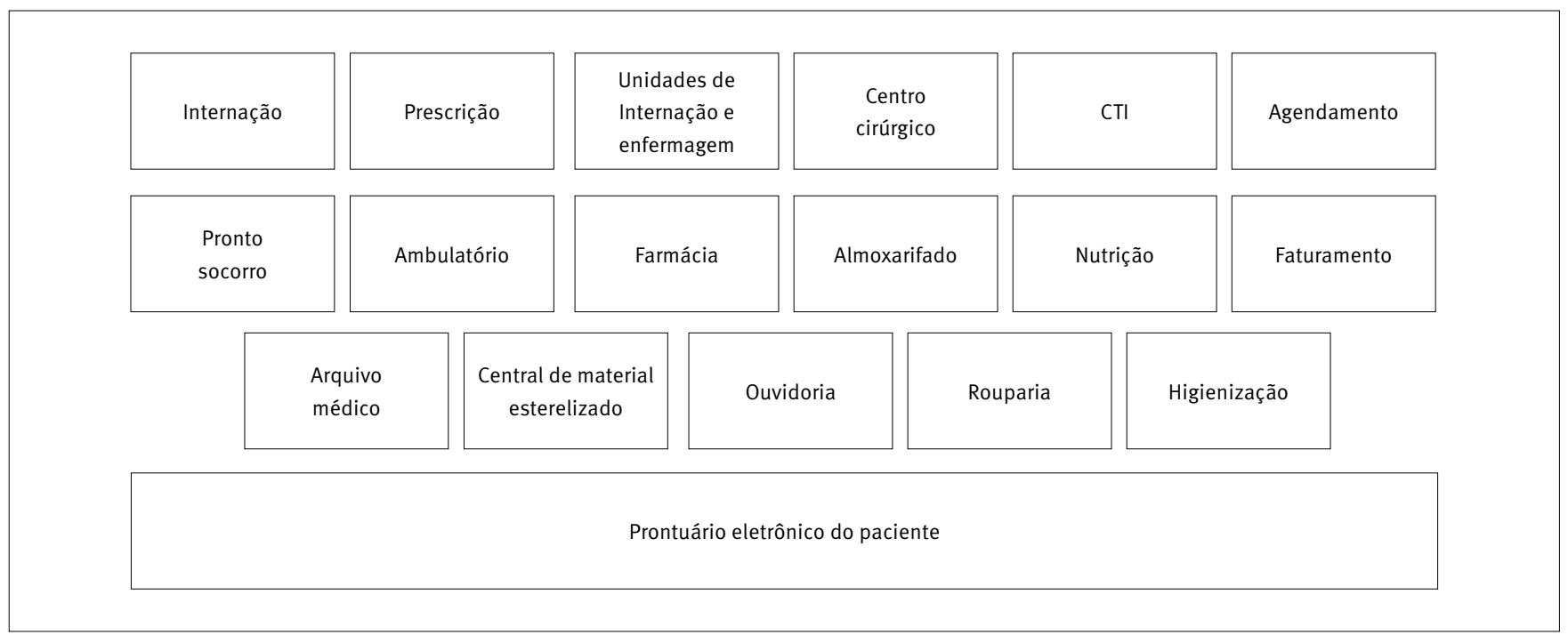


Os Analistas também definiram os “Usuários” do E-Hosp como os servidores públicos lotados no HPT, quais sejam médicos, enfermeiros, outros profissionais de saúde e administradores. Ou seja, os trabalhadores do hospital foram definidos como usuários do sistema, os quais deveriam registrar e recuperar informações no sistema, por meio de rotinas propostas pelos Analistas. De acordo com uma apresentação feita pelos Analistas, os Usuários deveriam apoiar a implantação para se beneficiarem das funcionalidades propostas pelo E-Hosp, mas os Analistas também reconheciam que poderia existir alguma resistência às mudanças, devido às novas rotinas do sistema.

Ademais, os Analistas também contavam com o apoio da Diretoria do HPT, i.e., o corpo de diretores responsável pela gestão do hospital, além de um assessor nomeado pelo MS especificamente para acompanhar o projeto. Segundo depoimento de um analista: "Temos forte apoio da direção do hospital para efetuarmos as mudanças necessárias”. Além disso, acreditavam que a
Diretoria tinha grande expectativa em relação às ferramentas de gestão que seriam disponibilizadas pelo sistema, como os relatórios gerenciais, e ao aumento de eficiência a ser viabilizado pelo novo modelo de gestão associado ao E-Hosp.

Em resumo, na fase de problematização, o Comitê Executivo desejava levar o HPT a um novo patamar de gestão, o qual demandava um melhor registro e recuperação das informações produzidas no dia a dia do hospital. Assim, apresentou o E-Hosp como uma ferramenta indispensável para alcançar tal objetivo e incumbiu os Analistas de implantarem o sistema no HPT. Além disso, no projeto de implantação, foram definidas as identidades dos demais atores - E-Hosp, Usuários e Diretoria. Desse modo, conforme apresentado na Figura 3, pode-se observar que os Analistas definiram o E-Hosp como um Ponto de Passagem Obrigatória (PPO), para o qual os outros atores deveriam se deslocar a fim de alcançar seus objetivos e, consequentemente, o sucesso na implantação do E-Hosp.

Figura 3. Estabelecimento do ponto de passagem obrigatória

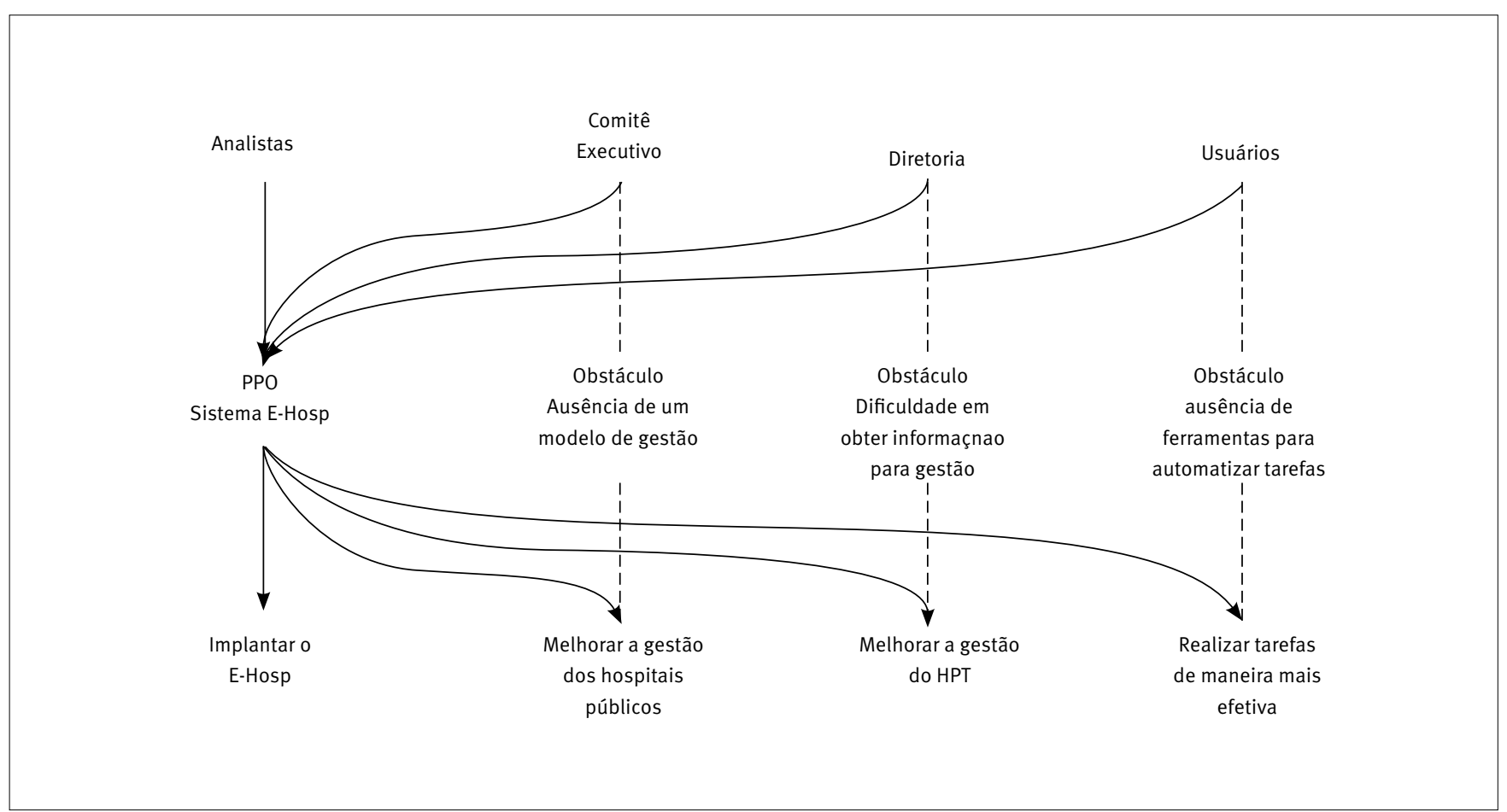

\section{“Interessamento"}

Após formularem hipóteses a respeito das identidades dos atores e de seus objetivos, os Analistas começaram a atrair a atenção dos demais atores para a implantação do E-Hosp por meio de uma série de dispositivos de "Interessamento". Primeiramente, foi realizada a reunião de abertura do projeto, na qual os Analistas apresentaram à Diretoria e aos Usuários as funcionalidades do sistema (Figura 2). Por exemplo, o conjunto dos módulos permitiria realizar operações como rastreabilidade de medicamentos e geração de relatórios gerenciais e do prontuário eletrônico do paciente, e assim levariam o HPT a um novo patamar de gestão. 
Além das funcionalidades do E-Hosp, foi apresentada a metodologia de gerenciamento do projeto. Segundo os Analistas, a metodologia proveria os mecanismos de monitoramento e controle das atividades, e orientaria o trabalho das equipes durante o projeto. Tal metodologia compreendia artefatos como matrizes de responsabilidade, comunicação e riscos, bem como um cronograma de atividades composto de quatro fases: 1) Iniciação; 2) Mapeamento dos Processos; 3) Treinamentos; e 4) Encerramento. Desse modo, ao se seguirem os passos propostos na metodologia, a implantação do E-Hosp alcançaria os objetivos propostos e, consequentemente, o sucesso. O projeto de implantação do E-Hosp, portanto, iniciou-se em outubro de 2010, com prazo de duração estimado em nove meses, ou seja, o E-Hosp deveria entrar em funcionamento no HPT em junho de 2011.

\section{Engajamento}

Após apresentarem os dispositivos de "Interessamento", os Analistas começaram a testar suas hipóteses formuladas na problematização em relação ao E-Hosp, à Diretoria e aos Usuários. Inicialmente, os Analistas solicitaram à Diretoria a indicação de usuários-chave que representariam os setores do HPT. Conforme mencionado por um dos Analistas: “[...] os usuários-chave devem conhecer a definição e entendimento dos processos [do E-Hosp] e atuar na facilitação de recursos funcionais para as atividades de projeto". Desse modo, em vez de negociarem o projeto com todos os funcionários do HPT, os Analistas testariam suas hipóteses diante de um conjunto menor de representantes da coletividade do hospital e esperavam reunir aliados para avançar na implantação do E-Hosp.

Em seguida, os Analistas iniciaram as entrevistas com os Usuários para mapear os processos de trabalho, com objetivo de definir as rotinas de uso do E-Hosp. Durante as entrevistas, além de compreender as atividades realizadas no dia a dia do HPT, os Analistas também deveriam explicar os objetivos e funcionalidades do E-Hosp. Contudo, os Usuários começaram a perceber que as funcionalidades do E-Hosp não atendiam a todas as suas expectativas. Por exemplo, no rol de funcionalidades do sistema, não estava presente a gestão financeira do estoque do medicamentos. De acordo com um Usuário: "tais funções financeiras são fundamentais para gestão de estoque no HPT".

Desse modo, os Analistas tentaram interessar os Usuários, bem como definir seus papéis e tarefas, com objetivo de enquadrá-los nas identidades propostas durante a problematização. Contudo, os Usuários não se interessaram de maneira automática. Conforme citado, a falta das funções financeiras no E-Hosp gerou descontentamento nos Usuários, os quais pleitearam a inclusão de tal módulo no escopo do projeto. Por outro lado, ter êxito no processo de "Interessamento" do E-Hosp para que a modificação de suas funções pudesse ser realizada não era uma tarefa trivial. De acordo com os Analistas, mudanças nas funções do E-Hosp, como a implantação do módulo de gestão financeira do estoque, dependiam do trabalho de uma fábrica de software e estavam condicionadas à deliberação do Comitê Executivo, o qual, após o início do projeto e as eleições presidenciais no Brasil, não se reuniu novamente.

Ao final do mapeamento dos processos de trabalho, em abril de 2011, os Analistas buscaram engajar os Usuários por meio da homologação dos processos mapeados. Tal artefato de homologação inscreveria o compromisso dos Usuários com os processos propostos pelos Analistas e suportados pelo E-Hosp em sua versão padrão na rede de atores. Entretanto, os Usuários elaboraram um relatório confrontando tais processos propostos pelos Analistas. Em tal relatório, pode-se ler: "verificou-se a necessidade de se adequar esses processos [processos do E-Hosp] às necessidades do HPT, considerando as atividades de reestruturação em andamento e as premissas do SUS". Entre as questões registradas no relatório, pode-se citar, em transcrição literal: "o sistema deve permitir o registro de custos e possuir funcionalidades para controle de custos de materiais e medicamentos".

Nesse estágio do projeto, e a despeito dos esforços dos Analistas em interessar os demais atores, Usuários e E-Hosp não se engajaram na negociação proposta. Com o silêncio do Comitê Executivo em relação ao projeto, tais atores pararam de suportar o empreendimento, aguardando sinalizações mais claras deste, a respeito do futuro do projeto. Os dispositivos propostos inicialmente - funcionalidades do sistema, metodologia de trabalho e homologação dos fluxos - não foram suficientes para engajar os demais atores no projeto. 0 sucesso do projeto não era algo evidente, visto que as hipóteses dos Analistas foram parcialmente refutadas.

Contudo, entre junho e setembro de 2011, novos dispositivos de "Interessamento" foram introduzidos no projeto. 0 Comitê Executivo reuniu-se novamente e passou a tomar decisões até então pendentes, tais como: a) solicitar aos Analistas a formulação de alternativas para as funções de gestão financeira no HPT; b) alterar o prazo de implantação para dezembro de 2011; e c) adquirir computadores e equipamentos para o HPT. Por fim, foi disponibilizado um formulário de solicitação de mudanças, visando acolher as demandas dos Usuários e deliberar sobre eventuais modificações nas funções do E-Hosp.

Após as mudanças citadas, os Usuários e E-Hosp aceitaram participar dos treinamentos e de uma atividade de prova de conceito proposta pelos Analistas, e, assim, voltaram a se engajar no projeto. Observa-se, então, que os novos dispositivos de 
“Interessamento" alteraram a configuração inicial do projeto, bem como viabilizaram a sua continuidade. Desse modo, o sucesso do projeto torna-se novamente algo factível.

Entre os meses de setembro e novembro de 2011, foram realizadas simulações de uso do E-Hosp no HPT. Tal etapa foi considerada exitosa, tornando o sucesso mais próximo, mesmo tendo os Usuários levantado algumas questões. A falta do módulo de gestão financeira no E-Hosp acarretou a manutenção do sistema legado e foi motivo de questionamento, conforme registrado nas notas de observação: “[...] a utilização do E-Hosp e do sistema legado em paralelo demandará maior quantidade de mão de obra qualificada a fim de evitar inconsistências nos dados dos dois sistemas". Ademais, a etiquetagem de medicamentos onerou o trabalho da farmácia, implicando dificuldades para atender às demandas do hospital. Nas enfermarias, o médicos alegaram que a prescrição eletrônica exigia digitação de muitos campos, enquanto os enfermeiros alegavam que "os processos de checagem de medicamentos no sistema são lentos, impactando no tempo de atenção aos pacientes".

Para todas essas questões, foram formuladas respostas dos mais diferentes tipos. Na farmácia, adquiriu-se uma máquina fracionadora de medicamentos para facilitar o trabalho de separação e etiquetagem dos medicamentos. Os médicos dividiram o trabalho de registro das prescrições com os residentes. Para os enfermeiros, foram adquiridos equipamentos leitores de código de barras para facilitar a checagem de medicamentos, bem como foram contratados digitadores para registrar as informações no sistema. Por fim, procedeu-se a mudanças nas funções do E-Hosp a fim de facilitar o registro de informações. Desse modo, pode-se notar que Analistas, E-Hosp, Usuários e Diretoria alteraram os processos propostos, as funcionalidades do E-Hosp e arranjos organizacionais, com objetivo de minimizar os questionamentos acima mencionados e viabilizar o início de uso do sistema no HPT. Ou seja, o alinhamento dos atores a um objetivo comum tornou o sucesso do projeto ainda mais palpável.

\section{Mobilização}

Durante o mês de novembro de 2011, foram realizadas reuniões semanais com a participação de Analistas, Diretoria e Usuários, a fim de planejar a "virada" do E-Hosp - um termo da área de TI que designa entrada em funcionamento. 0 momento da "virada" é um dispositivo introduzido pelos Analistas a fim de assegurar o compromisso com o uso do sistema, e, assim, o sucesso na implantação do E-Hosp estaria praticamente definido. Em tais reuniões, os atores envolvidos no projeto concluíram que não seria possível "virar" todos os módulos do E-Hosp ao mesmo tempo. Os Analistas, então, sugeriram fazer a "virada" dos módulos
Interação, Prescrição Eletrônica, Enfermarias, Farmácia e Almoxarifado. Os demais seriam, portanto, implantados em uma etapa futura do projeto.

Assim, ao final de novembro de 2011, aconteceu a "virada" dos módulos citados e o E-Hosp entrou em funcionamento no HPT. Os Usuários passaram a utilizar os módulos disponíveis, mas continuaram negociando com os Analistas mudanças no E-Hosp, conforme observado nos documentos de solicitação de mudanças: “desenvolver relatório de log para identificar o intervalo de tempo entre prescrição pelo Médico e a liberação da prescrição pela Enfermagem”, “informar campo saldo no gerenciador de dispensação de medicamentos”, “criar filtros de busca para o Almoxarifado".

Ademais, a Diretoria do HPT, durante uma reunião de acompanhamento do projeto, definiu o E-Hosp como o sistema oficial do hospital. Em reunião do Comitê Executivo, foram apresentados os resultados da implantação, bem como um plano para implantação dos demais módulos. Assim, a implantação do E-Hosp foi classificada como bem-sucedida, não obstante os diversos problemas que surgiram durante o projeto. Após essa reunião, o Comitê Executivo renovou o contrato com a empresa, postergando a implantação dos demais módulos E-Hosp no HPT para dezembro de 2012. Além disso, o MS passou a fazer planos de expandir o uso do E-Hosp para outros hospitais públicos.

Nesse momento, nota-se que todos os atores chegam ao consenso de que a implantação do E-Hosp foi um sucesso. Os Usuários, embora tenham feito críticas, passaram a utilizar o sistema na rotina do HPT. O E-Hosp, embora tenha passado por mudanças, funciona em praticamente todos os computadores do HPT, tendo mais de mil usuários. A Diretoria do HPT passa a utilizar os relatórios do sistema nas suas atividades de gestão. O Comitê Executivo passa a planejar a expansão do E-Hosp. E, por fim, os Analistas são deslocados para outros projetos semelhantes pelo País.

\section{DISCUSSÃO}

Como visto na seção anterior, a implantação do E-Hosp no HPT foi marcada por mudanças no projeto original e situações não previstas em seu início. Durante a implantação, constata-se que o sucesso do E-Hosp foi uma hipótese formulada pelos Analistas de Sistema, a qual foi submetida a diversos testes e negociações, à medida que foram introduzidos dispositivos de "Interessamento" no projeto. Assim, pode-se observar, na Figura 4, que o processo de tradução (Callon, 1986) permitiu compreender como o sucesso na implantação do E-Hosp foi construído pelos diversos atores envolvidos. 
Figura 4. Representação gráfica dos momentos de tradução

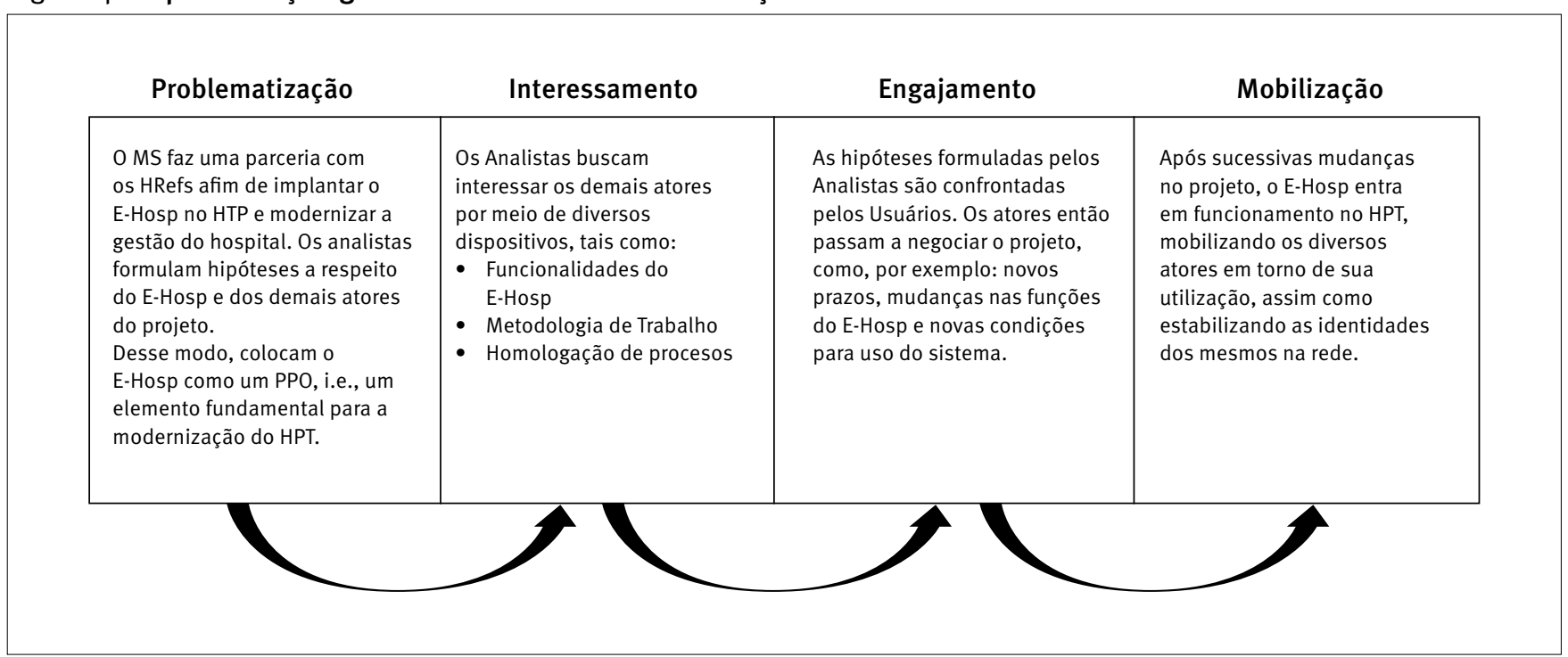

Também é importante ressaltar que, antes da implantação do E-Hosp, os atores estavam dispersos, o sistema E-Hosp jamais havia sido mencionado no HPT, não existia um Comitê Executivo, os Analistas não eram uma equipe e os trabalhadores do HPT não eram Usuários do sistema. Assim, à medida que a implantação do sistema E-Hosp se desenrola, as identidades desses grupos são formuladas, testadas, confrontadas e estabilizadas. Ao final desse processo, estabelece-se uma rede que associou o E-Hosp, o Comitê Executivo, os Analistas, a Diretoria e os Usuários. Observa-se, também, que esses grupos passaram a ter identidades bem definidas e concordaram que a implantação foi bem-sucedida, credenciando o MS a utilizar essa experiência como exemplo para outros hospitais.

Conforme citado, os estudos recentes sobre SIS nos países em desenvolvimento buscam compreender o estabelecimento de rede de atores que suportem a sustentação e expansão de sistemas em uma região ou país (Braa et al., 2004; Sahay et al., 2013; Sheikh \& Braa, 2011). Este estudo vem complementar as pesquisas existentes, ao evidenciar a heterogeneidade dos mecanismos empregados na construção do conceito de sucesso e da rede de suporte ao SIS, como: as funcionalidades do sistema, a metodologia de implantação, a homologação de processos, o formulário de solicitação de mudanças e a "virada" do sistema. Desse modo, pode-se argumentar que o sucesso, sustentação e expansão dos SIS estão condicionados aos instrumentos empregados durante a sua implantação, muitos deles não previstos no início do projeto.

Ademais, atestar o sucesso do projeto foi uma etapa fundamental para o Comitê Executivo propor a expansão do E-Hosp a outros hospitais do País. Dessa forma, pode-se observar que o fechamento da caixa preta (Latour, 1997) do E-Hosp no HPT permitiu que ela fosse transportada para outros locais. Isto é, um caso exitoso credenciou a implantação e uso do E-Hosp em outros hospitais. Contudo, tal transposição não será, provavelmente, suave, visto que, em um novo hospital, um novo processo de tradução se iniciará. Dessa forma, este estudo se alinha a Braa et al. (2004), defendendo serem necessárias estratégias flexíveis para adaptar o SIS a cada local. Ademais, os gestores de SI devem estar atentos às controvérsias que emergem ao longo do projeto e, em vez de interpretá-las como desvios dos objetivos originais, identificar oportunidades contidas nesses momentos de questionamento.

Na literatura científica brasileira e da América Latina sobre $\mathrm{SI}$, os estudos baseados na ANT registram, em detalhes, as diversas operações heterogêneas associadas ao desenvolvimento e implantação de SI (Andrade \& Urquhart, 2010; Cavalheiro \& Joia, 2014; Teles \& Joia, 2011). Este estudo vai ao encontro desses trabalhos precedentes, ao evidenciar que na saúde, assim como em outras áreas, a complexidade sociotécnica dos SI também se faz presente. Adicionalmente, diferentemente de estudos prévios que detectaram divergências na transferência de um país para outro (Braa et al., 2004; Cavalheiro \& Joia, 2014), na saúde, observa-se controvérsias dentro do mesmo país. Desse modo, pode-se sugerir que é bastante complexa a realidade da saúde no Brasil. Assim, quando um SIS é transportado de um local para outro, as diferenças são confrontadas, gerando controvérsias, as quais não devem ser entendidas como desvios de projeto, mas, sim, como momentos para entendimento da realidade que está se formando em uma rede sociotécnica. 


\section{CONCLUSÕES}

O presente estudo analisou a implantação de um SIS em um hospital público brasileiro, fundamentando-se na Teoria Ator-Rede. Assim, a pesquisa evitou estabelecer categorias prévias para definir os atores e o sucesso do projeto, concentrando-se em descrever como os atores se definem à medida que o projeto acontece e como eles negociam o conteúdo do projeto por meio de controvérsias ocorridas ao longo da implantação do sistema. Ou seja, a implantação do SIS foi uma construção coletiva, cujo sucesso foi definido à medida que os atores interagiram entre si.

Portanto, observa-se que a noção de sucesso, em vez de ser um constructo claro, possui uma definição problemática, já que, embora a maioria dos objetivos iniciais do projeto não tenha sido alcançada, ao final, a implantação foi considerada exitosa. Ou seja, como já dito, o sucesso foi construído à medida que controvérsias foram resolvidas e o sistema tornou-se estável na rotina dos trabalhadores do hospital.

Por meio de uma análise detalhada e longitudinal do caso, baseada na ANT, também foi possível observar que o projeto de implantação do E-Hosp foi uma hipótese formulada pelos Analistas no início do empreendimento, o que configurou o sistema como um PPO para todos os demais atores. Durante a implantação do sistema, a proposta dos Analistas foi submetida a provas de força e suscitou controvérsias, as quais foram resolvidas à medida que dispositivos de "Interessamento" foram introduzidos, por exemplo, a renegociação do prazo e escopo do projeto, a incorporação de novos módulos, a modificação de funções do sistema e mudanças nas condições de trabalho do hospital. Finalmente, o uso do sistema no hospital foi estabilizado e a implantação, considerada exitosa.

Desse modo, também é possível concluir que o sucesso do SIS não ocorreu somente em função das suas características técnicas, como pregavam os Analistas de Sistema, mas por meio de negociações entre os diversos atores da rede. Tal característica não é peculiar apenas a este caso, já que, como argumentam outros autores, projetos de SI, em vez de serem considerados meros empreendimentos técnicos, devem levar em conta, por exemplo, o conjunto heterogêneo de elementos sociais, econômicos e políticos intrínsecos a essas iniciativas (Avgerou, 2010; Braa et al., 2004).

Espera-se, portanto, que este estudo suscite reflexões sobre as práticas relacionadas à implantação de SIS no Brasil. Como um estudo crítico-interpretativo, este trabalho busca levar os desenvolvedores de SIS, como levou os autores, à reflexão acerca da complexidade sociotécnica do ambiente da saúde. Assim, além de buscar os objetivos estabelecidos nos projetos de SIS, também é necessário compreender como a implantação desses sistemas afetará a vida das pessoas envolvidas e, eventualmente, repensar as hipóteses inicialmente formuladas.

A Teoria Ator-Rede é uma abordagem heterodoxa em uma academia de SI majoritariamente positivista. Embora estudos baseados na ANT apareçam com alguma regularidade desde os anos 1990, a opção por essa abordagem é importante para alargar os horizontes teóricos do campo de SI. Dessa forma, este estudo busca contribuir para uma comunidade de estudos em SI mais plural, adotando uma abordagem que pode trazer novas questões de pesquisa para o campo de SI, já que a ontologia da ANT, baseada em redes heterogêneas e abordagem longitudinal, oferece uma maneira alternativa de olhar os problemas relacionados aos $\mathrm{SI}$.

Outrossim, nota-se que os estudos na área de SI que adotam a ANT como abordagem de pesquisa, inclusive este, buscam utilizar conceitos clássicos já definidos pelos principais autores da ANT, enquadrando a implantação de sistemas nos quatro momentos de tradução. Não se observa, assim, preocupação clara em expandir os horizontes de uso da ANT, algo preconizado pela liberdade empírica de tal abordagem. Assim, convidam-se os pesquisadores a explorarem novos rumos da ANT, como performação (Callon, 2006) e fóruns híbridos (Callon, Lascoumes, \& Barthe, 2009), de modo que novos conceitos sejam trazidos para os estudos em SI.

Finalmente, este estudo busca clarear questões teóricas sobre o cenário brasileiro de SIS. Estudos acerca da implantação de SIS em países em desenvolvimento analisaram diversas nações na África e Ásia. Contudo, a América Latina ainda é pouco discutida na área. Pozzebon, Diniz, e Reinhard (2011), a partir de uma perspectiva brasileira, enfatizam a importância de se constituir uma comunidade de pesquisa em SI forte, baseada em problemas teóricos relacionados à realidade do País, mas que mantenha diálogo construtivo com outros centros de produção de conhecimento. Portanto, este estudo, ao evidenciar controvérsias entre os atores e apresentar a dinâmica de implantação de um SI em uma organização pública, visa contribuir para a construção dessa tão sonhada e necessária comunidade brasileira de pesquisa em SI.

\section{AGRADECIMENTOS}

Os autores agradecem ao CNPq pelo apoio no desenvolvimento da pesquisa que resultou neste artigo. 


\section{REFERÊNCIAS}

Albuquerque, J. P. (2012). Flexibilidade e modelagem de processos de negócio: uma relação multidimensional. RAE-Revista de Administração de Empresas, 52(3), 313-329.

Albuquerque, J. P. D., Prado, E. P. V., \& Machado, G. R. (2011). Ambivalent implications of health care information systems: A study in the Brazilian public health care system. RAE-Revista de Administração de Empresas, 51(1), 58-71.

Andrade, A. D., \& Urquhart, C. (2010). The affordances of actor network theory in ICT for development research. Information Technology \& People, 23(4), 352-374.

Avgerou, C. (2010). Discourses on ICT and development. Information Technologies \& International Development, 6(3), 1-18.

Barbosa, A. F. (2008). Governo eletrônico: Dimensões da avaliação de desempenho na perspectiva do cidadão. Tese de doutorado, EAESP, FGV, São Paulo, Brasil.

Benbasat, I., Goldstein, D., \& Mead, M. (1987). The case research strategy in studies of information systems. MIS Quarterly, 11(3), 369-386.

Braa, J., Monteiro, E., \& Sahay, S. (2004). Networks of action sustainable health information systems across developing countries. MIS Quarterly, 28(3), 337-362.

Callon, M. (1986). Some elements of a sociology of translation: Domestication of the scallops and the fisherman of St Brieuc Bay. In J. Law (Ed.). Power action and belief a new sociology of knowledge (pp. 196223). London: Routledge.

Callon, M. (2006). What does it mean to say that economics is performative? In D. Mackenzie, F. Muniesa, \& L. Siu (Ed.). Do economists make markets? On the performativity of economics (pp. 311-357). Princeton: Princeton University Press.

Callon, M., Lascoumes, P., \& Barthe, Y. (2009). Acting in an uncertain world: An essay on technical democracy. Cambridge, Massachusetts: The MIT Press.

Cavalheiro, G. M., \& Joia, L. A. (2014). Examining the implementation of a European patent management system in Brazil from an actor-network theory perspective. Information Technology for Development. Doi: $10.1080 / 02681102.2014 .910634$

Ciborra, C. U., \& Hanseth, O. (1998). From tool to Gestell: Agendas for managing the information infrastructure. Information Technology \& People, 11(4), 305-327.

Doolin, B., \& Lowe, A. (2002). To reveal is to critique: Actor-network theory and critical information systems research. Journal of Information Technology, 17(2), 69-78.

Heeks, R., Mundy, D., \& Salazar, A. (1999). Why health care information systems succeed or fail [Paper n. 9]. Center for Development Informatics, Manchester.

Heeks, R., \& Stanforth, C. (2007). Understanding e-government project trajectories from an actor-network perspective. European Journal of Information Systems, 16(2), 165-177.

Joia, L. A., \& Magalhães, C. (2009). Implementation of an electronic prescription system in a Brazilian general hospital: Understanding sources of resistance. Electronic Journal on Information Systems in Developing Countries, 39(2), 1-18.

Kimaro, H. C., \& Nhampossa, J. L. (2005). Analyzing the problem of unsustainable health information systems in less-developed economies:
Case studies from Tanzania and Mozambique. Information Technology for Development, 11(3), 273-298.

Latour, B. (1997). Ciência em ação: Como seguir cientististas e engenheiros sociedade afora. São Paulo: Editora Unesp.

Latour, B. (2010). Cogitamus: Six lettres sur les humanités scientifiques. Paris: La Decouverte.

Law, J. (1999). After ANT: Complexity, naming and topology. In j. Law \& j. Hassard (Ed.). Actor-network theory and after (pp. 1-14). Oxford: Blackwell.

Marques, I. C. (2004). Uma história suficientemente respeitável sobre novos espaços de possibilidade para a inovação tecnológica na América Latina. Convergência, (35), 51-78.

Mitev, N. N. (2006). Postmodernism and criticality in information systems research: What critical management studies can contribute. Social Science Computer Review, 24(3), 310-325.

Paré, G. (2004). Investigating information systems with positivist case study research. Communications of the Association for Information Systems, 13(18), 233-264.

Pozzebon, M. (2004). Conducting and evaluating critical interpretive research: examining criteria as a key component in building a research tradition. In B. Kaplan, D.P. Truex, D. Wastell, A.T. Wood-Harper \& J. DeGross. (Ed.). Information systems research: Relevant theory and informed practice (pp. 275-292). London: Kluwer Academic Publishers.

Pozzebon, M., Diniz, E., \& Reinhard, N. (2011). Creating a Brazilian school in international information systems research: Opportunities and challenges. RAE-Revista de Administração de Empresas, 51(1), $10-14$.

Rajão, R., \& Vurdubakis, T. (2013). On the pragmatics of inscription: Detecting deforestation in the Brazilian Amazon. Theory, Culture \& Society, 30(4), 151-177.

Ramos, E. A. (2009). Remontando a política pública: A evolução da política nacional de informática analisada pela ótica da teoria do atorrede. Tese de doutorado, EBAPE, FGV, Rio de Janeiro, Brasil.

Sahay, S., Sæbø, J., \& Braa, J. (2013). Scaling of HIS in a global context: Same, same, but different. Information and Organization, 23(4), 294-323.

Sarker, S., Sarker, S., \& Sidorova, A. (2006). Understanding business process change failure: An actor-network perspective. Journal of Management Information Systems, 23(1), 51-86.

Sheikh, Y., \& Braa, K. (2011). Mobilising local networks of implementers to address health information systems sustainability. Electronic Journal on Information Systems in Developing Countries, 48(6), 1-21.

Silva, L. (2007). Institutionalization does not occur by decree: Institutional obstacles in implementing a land administration system in a developing country. Information Technology for Development, 13(1), 27-48.

Sun, V. (2010). Contribuição ao estudo da evolução de infraestruturas de informação: um caso de sistema hospitalar. Tese de doutorado, FEA, USP, São Paulo, Brasil.

Teles, A., \& Joia, L. A. (2011). Assessment of digital inclusion via the actornetwork theory: The case of the Brazilian municipality of Piraí. Telematics and Informatics, 28(3), 191-203.

Walsham, G. (1995). Interpretive case studies in IS research: Nature and method. European Journal of Information Systems, 4(2), 74-81.

Walsham, G. (1997). Actor-network theory and current status and future prospects. In A. S. Lee, J. Liebenau, \& J. I. Degross (Ed.). Information systems and qualitative research (pp. 466-480). London: Chapman Hall. 